\title{
FLEXIBLE FIBREOPTIC BRONCHOSCOPY IN THE REMOVAL OF LONG STANDING FOREIGN BODY: 2 CASE REPORTS
}

T. Dhanasekar1, Pankul Mangla², Puneet K. Nagendra3, B. Rajagopalan ${ }^{4}$

\section{HOW TO CITE THIS ARTICLE:}

T. Dhanasekar, Pankul Mangla, Puneet K. Nagendra, B. Rajagopalan. "Flexible Fibreoptic Bronchoscopy in the Removal of Long Standing Foreign Body: 2 Case Reports". Journal of Evolution of Medical and Dental Sciences 2015; Vol. 4, Issue 06, January 19; Page: 1076-1079, DOI: 10.14260/jemds/2015/152

ABSTRACT: Two cases of chronic foreign body aspiration were treated in our hospital. Management of the foreign body aspiration was challenging in them as the symptoms were discrete and persisted for as long as 20 years and in one of the cases there was failure of retrieving the foreign body elsewhere. We share our experience in using flexible fibreoptic bronchoscope for removal of retained foreign body. This further emphasizes that flexible bronchoscopy is a successful therapeutic option if carried out using appropriate instruments by extremely skilled personnel in an adequate hospital setup and in selected cases.

KEYWORDS: Bronchoscopy, Retained foreign bodies.

INTRODUCTION: Foreign body aspiration is more common in children than in adults.[1] Clinical manifestations and roentgenograms are nonspecific in chronic cases.[2] We report two chronic cases of foreign body aspiration as long as 20 years. These two cases are unusual as there is delayed and innocuous presentation even after aspiration of such a large foreign body. It stresses upon the fact that healthy adults may tolerate aspiration of foreign bodies for a long duration without any lifethreatening events. Though conventionally rigid bronchoscope is used, flexible fibreoptic bronchoscopy is a successful therapeutic option in selected cases.[3]

\section{CASE REPORTS:}

Case 1: A 34 year old man, non-smoker and with no known co morbidities presented with productive cough for more than 20 years. The symptoms had become much worse over the last six months. He came to our hospital with the complaint of bloody and purulent sputum. Five years ago, he was diagnosed as a case of aspirated foreign body in the right bronchus in another hospital. There was a failure in the retrieval of foreign body by rigid bronchoscopy in that hospital. Thus he was advised surgical removal by them. Having denied the procedure, patient was symptomatically managed elsewhere until he presented to us.

Clinical examination was unremarkable. Chest radiograph revealed opacity in the right hilar region with middle and lower lobe collapse on same side [Figure 1a]. Computed tomography of thorax depicted a radiopaque object at the origin of bronchus intermedius causing complete collapse of right middle lobe with lower lobe brochiectatic changes. Review of prior radiographs showed that the right lower lobe collapse had been present for the past 5 years.

Flexible fibreoptic bronchoscopy under topical anaesthesia revealed a foreign body lodged in the bronchus intermedius with granulation tissue around it [Figure 1b]. With the help of biopsy forceps, the granulation tissue was excised and the foreign body was mobilized. Several attempts were made to remove the foreign body with different types of forceps like alligator forceps, basket forceps, biopsy forceps; but the foreign body could not be retrieved as there was a web like projection 


\section{CASE REPORT}

nearby. The web was incised with electrocautery and the foreign body was removed with a rat tooth cutting forceps. It was found to be a hollow cylindrical object made of plastic [Figure 1c]. The patient was shown the foreign body. On further enquiry, he recalled that he had accidentally aspirated plastic bottle cap 20 years ago, while he was playing with it.

Case 2: A 50 year old woman presented with dry cough since 2 months. Physical examination was unremarkable. On further evaluation, chest radiograph showed a linear opacity near the right hilum [Figure 2a]. This was confirmed with computed tomogram of thorax, which revealed a radiopaque object in right middle lobe bronchus. She underwent flexible fibreoptic video bronchoscopy. A foreign body in the medial segment of right middle lobe was found [Figure 2b]. Rat tooth cutting forceps was used to grasp and pull out the foreign body. The foreign body was found to be a gold nose stud screw [Figure 2c]. On viewing the nose stud, the patient remembered of having it lost some 16 years ago.

DISCUSSION: Limper and Prakash reviewed their 33 yr experience in the Mayo Clinic, with 60 cases of non-asphyxiating tracheobronchial foreign bodies in adults and concluded that foreign body aspiration into the lower airways of adults without predisposing factors is uncommon, and the diagnosis is usually made long after the actual event of aspiration.[1] In both of our cases also the patients had no predisposing factors and diagnosis was made long after the event had occurred

R-S. Lan in his study of 47 adult patients has classified foreign bodies based on duration of aspiration. ${ }^{4]}$ The mean duration of residence of foreign body was 25.8 months; where as in our case one of the patients had it for more than 20 years. He concluded that chronic cases of foreign body aspiration were diagnosed only with a high clinical index of suspicion. In our case we proceeded with high index of suspicion even when there was no history of choking. Baharloo F et al categorizes foreign bodies into two types, organic and inorganic; after studying 112 patients over 20 years.[5] They observed that in adults inorganic foreign bodies are more common. Organic foreign body swells in size and undergoes lipoid necrosis and cause chemical bronchitis, fever and chest infections. Inorganic foreign bodies such as coins, pins, small parts of toys, pen caps and others cause tissue reaction and formation of granulation tissue. [6] In one of our case, the gold nose stud being an inert material, there was no formation of granulation tissue around it even after 16 years. But there was granulation tissue formation around the plastic object in another case.

Pinto a et al studied 31 adult patients in a 5 year period and concluded that plain chest radiograph is the initial modality in diagnosis of suspected foreign body aspiration. ${ }^{[7]}$ Radiopaque materials like metal, teeth etc can be identified. Organic materials are not radiopaque. Non-specific radiological findings like air trapping, atelectasis and obstructive pneumonia may be present. However, if the history is suggestive, a normal chest radiograph does not rule out a diagnosis of foreign body aspiration. ${ }^{[6]}$ Just as in our case there was collapse of the lung parenchyma. Computed tomography of chest should be done to determine the exact location of foreign body and to detect unsuspected aspirated foreign body.

Baharloo $\mathrm{F}$ et al successfully retrieved the foreign body through rigid bronchoscope in $92 \%$ (103 cases) of his cases and through flexible bronchoscope in $8 \%$ (9 cases).[5] We have used flexible fibreoptic bronchoscopy under local anesthesia in both the cases. Various instruments can be used such as dormet forceps, snare forceps, alligator forceps, biopsy forceps, rat tooth cutting forceps and Fogarthy catheter for removal. Baharloo F et al used Alligator or biopsy or peanut-type forceps. We 


\section{CASE REPORT}

made use of Rat tooth cutting forceps. We should remember that while removing the impacted foreign body, it may obstruct at the main stem bronchus and cause accidental migration into contralateral lung due to inefficient grasps. Inorganic foreign bodies have sharp edges and may cause damage to the airway mucosa resulting in bleeding. Once foreign body is removed; entire tracheobronchial tree should be checked for injuries and residual fragments, especially the organic foreign body like a peanut, corn etc.[5] This further emphasizes that flexible bronchoscopy is a successful therapeutic option if carried out using appropriate instruments by extremely skilled personnel in an adequate hospital setup and in selected cases.

Though the majority of foreign body aspirations present characteristically, few can be clinically stable as seen in our case. We thus suggest that diagnostic bronchoscopy should be considered in all undiagnosed cases of chronic cough with high index of clinical suspicion.

\section{REFERENCES:}

1. Limper AH, Prakash UB. Tracheobronchial foreign bodies in adults. Ann Intern Med 1990; 112: $604-609$.

2. Patel S, Kazerooni EA. Case 31: foreign body aspiration-chicken vertebra. Radiology 2001; 218: 523-5.

3. C. H. Chen, C. L. Lai, T. T. Tsai, Y. C. Lee, and R. P. Perng, Foreign body aspiration into the lower airway in Chinese adults. Chest 1997; 112: 129-133.

4. R-S. Lan. Non-asphyxiating tracheobronchial foreign bodies in adults. Eur Respir J 1994; 7: 510 514.

5. Baharloo F, Veyckemans F, Francis C, Biettlot MP, Rodenstein DO. Tracheobronchial Foreign bodies: presentation and management in children and adults. Chest1999; 115: 1357-62.

6. Mahmoud M, Imam S, Patel H, King M. Foreign body aspiration of a dental bridge in the left main stem bronchus. Case Rep Med 2012; 2012: 798163.

7. Pinto A, Scaglione M, Pinto F, et al. Tracheobronchial aspiration of foreign bodies: current indications for emergency plain chest radiography. Radiol Med (Torino) 2006; 111: 497-506.

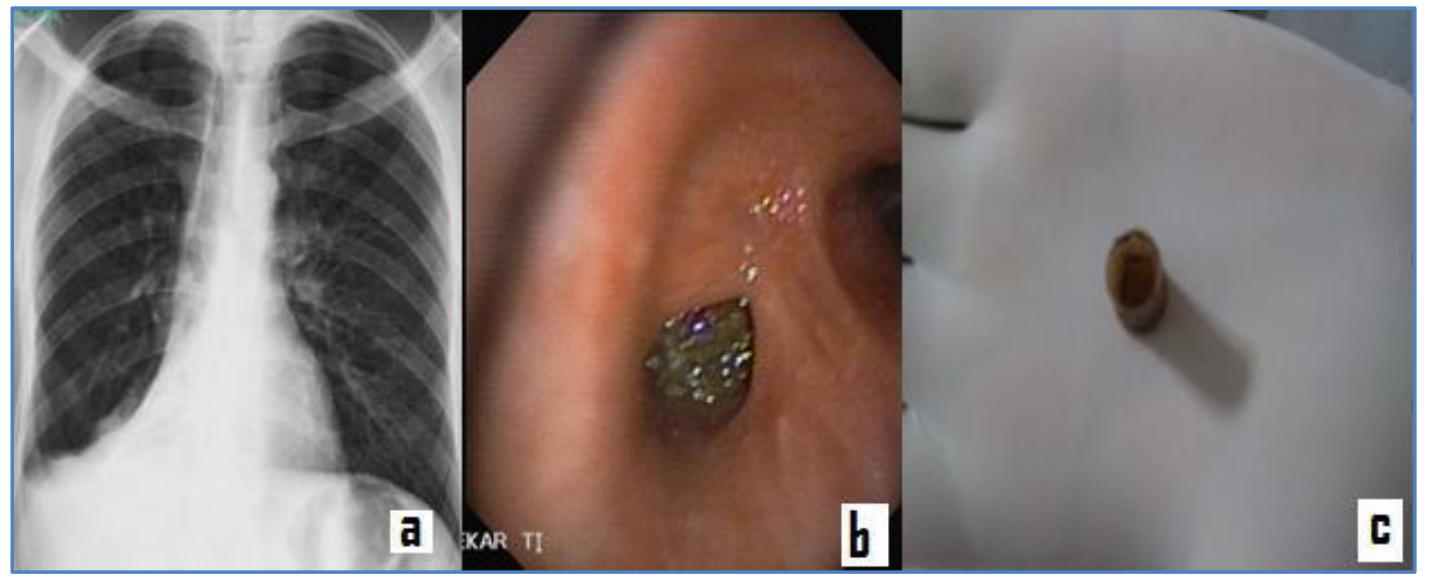

Figure 1: (a) Chest radiograph showing opacity in the right hilar region with middle and lower lobe collapse on same side; (b) FOB picture showing foreign body in the bronchus intermedius; (c) hollow cylindrical object made of plastic 


\section{CASE REPORT}

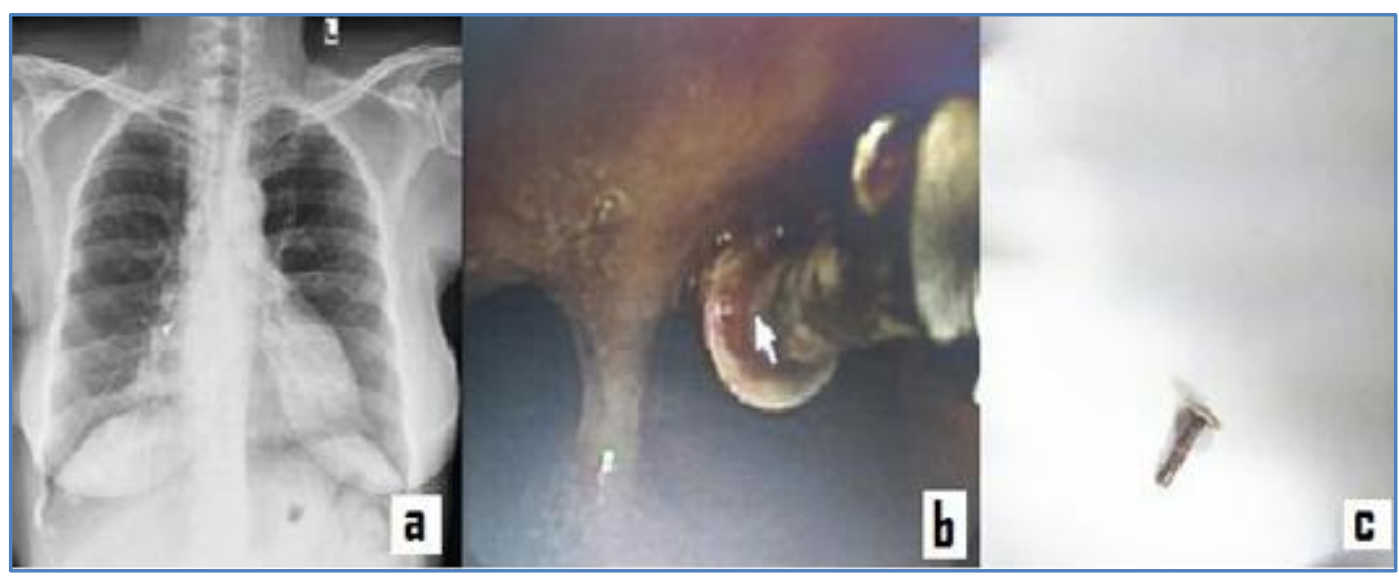

Figure 2: (a) Chest radiograph with a linear opacity near the right hilum. (b) FOB picture showing foreign body in the medial segment of right middle lobe (c) gold nose stud screw.

\section{AUTHORS:}

1. T. Dhanasekar

2. Pankul Mangla

3. Puneet K. Nagendra

4. B. Rajagopalan

\section{PARTICULARS OF CONTRIBUTORS:}

1. Associate Professor, Department of Pulmonary Medicine, Sri Ramachandra University, Chennai, India.

2. Post Graduate, Department of Pulmonary Medicine, Sri Ramachandra University, Chennai, India.

3. Post Graduate, Department of Pulmonary Medicine, Sri Ramachandra University, Chennai, India.
4. Professor \& HOD, Department of Pulmonary Medicine, Sri Ramachandra University, Chennai, India.

\section{NAME ADDRESS EMAIL ID OF THE CORRESPONDING AUTHOR:}

Dr. T. Dhanasekar, \# AJ-147, No. 3, Golden Aster Apartments, $9^{\text {th }}$ Main Road, Anna Nagar, Chennai-600040.

E-mail: drdhansekar@yahoo.com

Date of Submission: 21/12/2014.

Date of Peer Review: 22/12/2014.

Date of Acceptance: 08/01/2015.

Date of Publishing: 19/01/2015. 